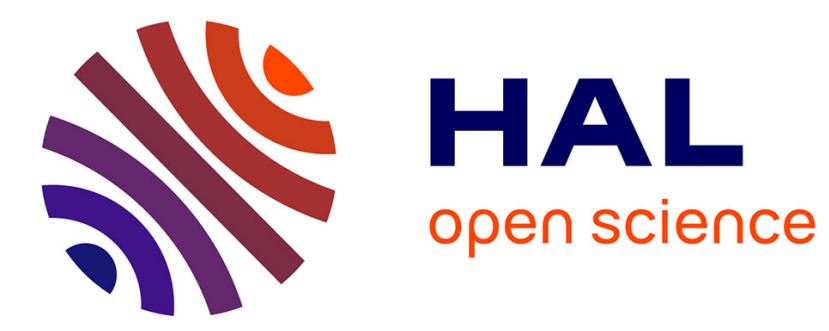

\title{
Determination of fatty acids and lipid classes in salmon oil by near infrared spectroscopy
}

\author{
Mari Merce Cascant, Cassandra Breil, Anne-Sylvie Fabiano-Tixier, Farid
}

Chemat, Salvador Garrigues, Miguel de La Guardia

\section{- To cite this version:}

Mari Merce Cascant, Cassandra Breil, Anne-Sylvie Fabiano-Tixier, Farid Chemat, Salvador Garrigues, et al.. Determination of fatty acids and lipid classes in salmon oil by near infrared spectroscopy. Food Chemistry, 2018, 239, pp.865-871. 10.1016/j.foodchem.2017.06.158 . hal-02621701

\section{HAL Id: hal-02621701 https://hal.inrae.fr/hal-02621701}

Submitted on 26 May 2020

HAL is a multi-disciplinary open access archive for the deposit and dissemination of scientific research documents, whether they are published or not. The documents may come from teaching and research institutions in France or abroad, or from public or private research centers.
L'archive ouverte pluridisciplinaire HAL, est destinée au dépôt et à la diffusion de documents scientifiques de niveau recherche, publiés ou non, émanant des établissements d'enseignement et de recherche français ou étrangers, des laboratoires publics ou privés. 


\title{
Determination of fatty acids and lipid classes in salmon oil by near infrared spectroscopy
}

\author{
Mari Merce Cascant ${ }^{\mathrm{a}, \mathrm{b}}$, Cassandra Breil ${ }^{\mathrm{b}}$, Anne Silvie Fabiano-Tixier ${ }^{\mathrm{b}}$, Farid Chemat ${ }^{\mathrm{b}}$, Salvador Garrigues ${ }^{\mathrm{a}, *}$, \\ Miguel de la Guardia ${ }^{a}$ \\ a Department of Analytical Chemistry, University of Valencia, 50 Dr. Moliner Street, Research Building, 46100 Burjassot, Valencia, Spain \\ ${ }^{\mathrm{b}}$ Université d'Avignon et des Pays de Vaucluse, INRA, UMR408, GREEN Team Extraction, 84000 Avignon Cedex, France
}

Keywords:

Near infrared spectroscopy

Partial least square

Fatty acids

Lipid class

Omega-3

Omega-6

\begin{abstract}
A B S T R A C T
Near-infrared (NIR) spectroscopy was evaluated as a rapid method for the determination of oleic, palmitic, linoleic and linolenic acids as well as omega-3, omega-6, and to predict polyunsaturated, monounsaturated and saturated fatty acids, together with triacylglycerides, diglycerides, free fatty acids and ergosterol in salmon oil. To do it, Partial Least Squares (PLS) regression models were applied to correlate NIR spectra with aforementioned fatty acids and lipid classes. Results obtained were validated in front of reference procedures based on high performance thin layer and gas chromatography. PLS-NIR has a good predictive capability with relative root mean square error of prediction (RRMSEP) values below or equal to $1.8 \%$ and provides rapid analysis without the use of any chemicals making it an environmentally friendly methodology.
\end{abstract}

\section{Introduction}

The determination of lipids and evaluation of fatty acids composition in foods is of a great importance for human health. Fish and shellfish are important sources of long-chain omega-3 polyunsaturated fatty acids (LCn-3PUFAs). A high intake of LCn-3PUFAs, produces beneficial effects in the human health reducing the impact of cardiovascular diseases, diabetes, cancer, obesity, autoimmune diseases, rheumatoid arthritis, asthma and depression (Lavie, Milani, Mehra, \& Ventura, 2009; Simopoulos, 2002; Patterson, Wall, Fitzgerald, Ross, \& Stanton, 2012).

The most important LCn-3PUFAs are eicosapentaenoic acid (EPA; C20:5n-3) and docosahexaenoioc acid (DHA; C22:6n-3) (Calder \& Yaqoob, 2009) although docosapentaenoic acid (DPA; C22:5n-3) can be also important (Kaur, Cameron-Smith, Garg, \& Sinclair, 2011), being $\alpha$-linolenic acid (ALA; C18:3n-3) the precursor of EPA and DHA (Kim, Nam, Sik, Hayes, \& Lee, 2014). On the other hand high intakes of long-chain omega- 6 polyunsaturated fatty acids (LCn-6PUFAs) have opposite properties than those of LCn-3PUFAs (Simopoulos, 2002) (Patterson et al., 2012), being Linoleic acid (LA; C18:2n-6) the precursor of arachidonic acid (AA; 20:4n-6) (Kim et al., 2014). OA is the major monounsaturated fatty acid (MUFA) present in salmon oil and belongs to the family

\footnotetext{
* Corresponding author.

E-mail address: salvador.garrigues@uv.es (S. Garrigues).
}

of omega- 9 fatty acids, being correlated the high MUFA content of fish oil with cardioprotective effects (Covaset al., 2006). On the contrary, Wu, Song, Xu, Zhang, and Zou (2007) demonstrated that palmitic acid (PA; C16:0) and OA affect cholesterol and fatty acid metabolism in an opposite manner than oleic acid. SFAs affect involved factors in cholesterol metabolism (Mensink, 2013). For the aforementioned reasons, a deep knowledge of the presence and concentration of lipids in fish oil is mandatory.

Salmon oil contains triglycerides (TAGs) as major components at a level of $75 \%$, diglycerides (DAGs) at $17 \%$ and monoglycerides (MAGs) as minor components. Additionally there are free fatty acids (FFAs) and ergosterol at levels of $6 \%$ and $2 \%$ of total lipids, respectively.

On the other hand, predominant fatty acids present in salmon oil are OA, LA, PA and ALA with values around 39\%, 17\%, $11 \%$ and $5 \%$, respectively. In general, total SFAs concern $20 \%$ of extracted oil while MUFAs and PUFAs are around 44\% and 34\%, respectively (Cascant et al., 2017).

Chromatography is the main technique commonly employed to determine fatty acids and lipids in fish oil samples. Thin-layer chromatography (TLC) and its refined version high-performance thin-layer chromatography (HPTLC) are frequently used in numerous separations, identification of the individual lipids and their quantitative determinations in foods (Fuchs, Süß, Teuber, Eibisch, \& Schiller, 2011). HPTLC technique is a sequential procedure that could not be fully automatized. Its use in lipid analysis involves 
the following steps: i) sample and standard preparation with chloroform solvent, ii) TLC plate conditioning, where silica gel plates are washed with a mixture chloroform/methanol and dried at $110^{\circ} \mathrm{C}$ for $60 \mathrm{~min}$, iii) application of sample and standards in TLC plate, iv) mobile phase preparation, which depends of lipid class determination, due to their differences in polarity of lipids, v) immersion of the stationary phase plate in mobile phase, vi) automatic developing distance, vii) final drying, viii) visualisation and, ix) quantitative evaluation of the generated densitometric data. In addition to time consuming, a possible lipid oxidation could be due based on TLC plate exposition to atmospheric oxygen and, the limitation of the preparative applications in TLC plate (Fuchs et al., 2011). On the other hand, fatty acids can be measured by using gas chromatography (GC) (Zhang, Wang, \& Liu, 2015; Laakso \& Hiltunen, 2002). Prior to the analysis by GC fatty acids are liberated from glycerides and converted to their methyl esters (FAMEs) which are more volatile than FFAs (Laakso \& Hiltunen, 2002; Morrison \& Smith, 1964). GC methods for fatty acids and lipids require several manipulative steps with high time and energy consume, which reduces their applicability for quality control in a sustainable way.

Fourier Transform-Infrared (FT-IR) spectroscopy in the middle region and Raman measurements have been used to predict the amount of omega- 3 and omega- 6 in melted fat from pork adipose tissue (Olsen, Rukke, Egelandsdal, \& Isaksson, 2008). Floriano Ribeiro, Peralta-Zamora, Pereira Ramos, and Pereira-Netto (2013) used mid and near infrared reflectance spectroscopy, with multivariate calibration, to predict LA and ALA content in flax seeds and flax seed flours. Cozzolino, Murray, Chree, and Scaife (2005) employed near infrared (NIR) spectroscopy with partial least squares (PLS) for the determination of FFA in fish oil and, Bekhit, Grung, and Mjøs (2014) investigated the potential of FT-IR, NIR and Raman spectroscopy, with PLS regression models to predict concentrations of EPA, DHA and omega-3 in fish oil supplements. Karlsdottir, Arason, Kristinsson, and Sveinsdottir (2014) evaluated the feasibility of using NIR spectroscopy to determine lipid composition of two lean fish species, hoki and saithe, namely total lipid content, phospholipid, PUFAs and MUFAs.

NIR spectroscopy, combined with chemometric tools, can provide an alternative to the chromatography methods to determine fatty acids, fatty acid families and lipid classes. NIR measurements are fast and non-destructive, they do not require any sample pretreatment step, nor the use of reagents and solvents, and not generates residues, making it an environmentally friendly methodologies. Moreover, NIR also allows the simultaneous determination of several analytes or parameters in a same sample from a single and direct measurement. Additionally, samples can be measured inside closed glass vials, thus avoiding sample alteration and crosscontamination. On concluding, NIR spectroscopy can be a good alternative to traditional methods due to their applicability for quality control in a sustainable way.

The aim of the present study has been to evaluate NIR technique in combination with partial least square for the simultaneous determination of i) fatty acids as OA, PA, ALA, LA, ii) fatty acid families as omega-3, omega-6, PUFAs, MUFAs and SFAs and, iii) lipid classes as TAGs, DAGS, FFAs and ergosterol in salmon oil. PLS-NIR regression models were built and assayed to evaluate the aforementioned parameters in oil extracts of salmon fish, being compared the predicted values with reference data obtained by HPTLC and CG-FID.

\section{Experimental}

\subsection{Materials, samples and reagents}

n-Hexane (HPLC grade), methanol, sulfuric acid, sodium chloride, chloroform, methyl acetate, acetic acid, diethyl ether and potassium chloride were of analytical grade and were supplied by VWR International (Darmstadt, Germany).

Atlantic Salmon (Salmon salar) samples were bought at the local market and were stored at $-20^{\circ} \mathrm{C}$. Samples were lyophilized, pulverized and stored in hermetic bags until extraction. Twenty-five grams of lyophilized salmon samples were extracted under reflux during $8 \mathrm{~h}$ with $300 \mathrm{~mL}$ of solvent. After this time, the content of the distillation flask was evaporated under reduced pressure by using a rotary evaporator (Cascantet al., 2017). A total of 54 salmon oil samples and mixtures of them were used in this study.

\subsection{Reference procedure}

\subsubsection{High Performance Thin Layer Chromatography (HPTLC)}

Lipid classes were obtained by using a High Performance Thin Layer Chromatography (HPTLC) from CAMAG (Muttenz, Switzerland). Lipids were detected and quantified using a CAMAG 3 TLC scanning densitometer with identification of the classes against known polar and neutral lipid standards. Lipid classes were identified and quantified using a calibration curve of each target molecule by using winCATS-Planar Chromatography Manager (version 1.3.3; CAMAG) for retention factor (Rf) and peak area of the calculations. Values obtained were expressed as percentage of lipid class in total lipids and used as reference for PLS-NIR models building (Cascant et al., 2017; Breil, Meullemiestre, Vian, \& Chemat, 2016).

Lipid extracts were loaded as spots onto $20 \times 10 \mathrm{~cm}$ silica gel 60 F254 HP-TLC plates from Merck (Darmstadt, Germany) using an ATS 5 automatic TLC sampler. HPTLC plates of silica gel 60 F254 were previously washed with a mixture of chloroform/methanol (2:1, v/v), followed by drying at $110{ }^{\circ} \mathrm{C}$ for $60 \mathrm{~min}$ on the TLC Plate Heater (CAMAG, Muttenz, Switzerland). A mixture of methyl acet ate/isopropanol/chloroform/methanol $/ \mathrm{KCl}(0.25 \%$ solution $)$ in a ratio of 25:25:25:10:9 $(v / v / v / v / v)$ was used as eluent to separate polar lipids running to a height of $7 \mathrm{~cm}$ from the origin. On another plate, a mixture of $n$-hexane/diethyl ether/glacial acetic acid, in a ratio of 70:30:2 $(v / v / v)$, was used till a height of $7 \mathrm{~cm}$ from the origin to separate neutral lipids. After drying, the plate was dipped for $2 \mathrm{~s}$ in a modified (10 $\mathrm{mg}$ of primuline, $160 \mathrm{~mL}$ of acetone, $40 \mathrm{~mL}$ of water), then scanned using a TLC Scanner 3 with WinCATs software (CAMAG).

Standard solutions were prepared using chloroform as solvent at concentration levels of $0.2 \mathrm{mg} \mathrm{mL}^{-1}$ of lipid in each solution. For samples, approximately $1 \mathrm{mg} \mathrm{mL}^{-1}$ of pure oil was obtained in chloroform. All solutions were stored in the dark at $-20{ }^{\circ} \mathrm{C}$ until their analysis.

\subsubsection{Gas chromatography}

Samples were prepared from extracted oils using acid-catalyzed trans-methylation (Morrison \& Smith, 1964). $400 \mu \mathrm{L}$ of triheptadecanoin (C17:0 TAG, from Sigma Aldrich) $2 \mathrm{mg} \mathrm{mL}^{-1}$ in hexane solution was used as internal standard. $1 \mathrm{ml}$ of methanolic sulfuric acid $(5 \% \mathrm{v} / \mathrm{v})$ was added to approximately $20 \mathrm{mg}$ of extracted oil and the mixture was heated at $85^{\circ} \mathrm{C}$ for $90 \mathrm{~min}$. When the solution reached the room temperature, $1.5 \mathrm{ml}$ of sodium chloride (0.9\%) and $1 \mathrm{ml}$ of $n$-hexane were added. The flask was shaken vigorously during $30 \mathrm{~s}$ before centrifugation at $4000 \mathrm{rpm}$ for $2 \mathrm{~min}$ and the organic layer was transferred to a GC vial before direct injection in the gas chromatograph.

Fatty acid methyl esters were separated, identified and quantified by using a 7820 A gas chromatography (GC) system from Agilent technologies (California, USA) using flame ionization detector (GC-FID) and autosampler. GC was performed by a BD-EN14103 capillary column $(30 \mathrm{~m} \times 0.32 \mathrm{~mm} \times 0.25 \mu \mathrm{m})$ using helium as carrier gas at the speed of $33 \mathrm{~cm} \mathrm{~s}^{-1} .2 \mu \mathrm{l}$ of samples were injected in split mode (split ratio: $1: 20$ ) a $250^{\circ} \mathrm{C}$. The oven temperature program was operated as follows: initial temperature at $50{ }^{\circ} \mathrm{C}$ for 
one minute, increasing at a rate of $20^{\circ} \mathrm{C} \mathrm{min}^{-1}$ to $180{ }^{\circ} \mathrm{C}$ and at a rate of $2{ }^{\circ} \mathrm{C} \mathrm{min}-1$ from $180{ }^{\circ} \mathrm{C}$ to $230^{\circ} \mathrm{C}$, held isothermally at $230^{\circ} \mathrm{C}$ for $10 \mathrm{~min}$. Data were collected with Agilent EZChrom Elite software and FAMEs were identified compared to purified FAME standards from Sigma-Aldrich Chimie. (Lyon, France) (Cascant et al., 2017; Breil et al., 2016; Sicaire et al., 2015).

Omega-3 is the sum of ALA, eicosatrienoic acid (ETE; C20:3n-3), EPA, DPA AND DHA, and Omega-6 the sum of LA, gamma-Linolenic acid (GLA; C18:3n-6), eicosadienoic acid (C20:2n-6), dihomogamma-linolenic acid (DGLA; C20:3n-6) and AA. PUFAs were established as the sum of all fatty acids that contain more than one double bond in their backbone, MUFAs were determined as the sum of fatty acids that have one double bond in their chain and SFAs as the sum of fatty acids with single bonds. These results were used as reference values in the multivariate regression analyses.

\subsection{NIR procedure}

A Fourier transform near infrared (FT-NIR) spectrometer, model Multipurpose Analyzer (MPA) from Bruker (Bremen, Germany was employed for transmission spectra acquisition. This instrument is equipped with a NIR source, a quartz beamsplitter and PbS detector. For instrumental and measurement control of the spectrometer, as well as for data acquisition, Opus 6.5 software from Bruker was used.

NIR transmission spectra of salmon oils were obtained in the range between 14,000 and $4500 \mathrm{~cm}^{-1}$ by using glass vials with $1 \mathrm{~mL}$ total volume and a band pass of $6 \mathrm{~mm}$. Each spectrum was acquired accumulating 50 scans by using an optical resolution of $4 \mathrm{~cm}^{-1}$. The background spectrum was acquired from an empty glass vial under the same instrumental conditions than those employed for sample measurements. Three measurements of each sample were obtained by rotating the sample vial position between replicates. Mean values of triplicate spectra of each sample were employed for building PLS calibration models and for sample predictive purposes.

\subsection{Chemometric data treatment}

Data treatment was done in Matlab 8.3.0.532 (R2014a) from Mathworks (Natick, MA, USA) using PLS Toolbox 7.5.2 from Eigenvector Research Inc. (Wenatchee, WA, USA) for principal analysis components (PCA), interval partial least squares (iPLS) and partial least squares (PLS) regression models.

To build PLS models, total data sample set was divided in two independent subsets: one used for calibration and the other one employed as a validation subset, with 38 and 16 objects, respectively. For this purpose, the Kennard-Stone (K-S) algorithm was used for the selection of the calibration set (Kennard \& Stone, 1969). PCA was used to ensure that calibration set was representative of all studied samples to obtain PLS-NIR models with a good predictive capability. Calibration models were developed based on the statistically inspired modification of the PLS method (SIMPLS) algorithm (de Jong, 1993).

Prior to build PLS-NIR models the spectral data were preprocessed. Different pre-processing methods were tested as multiplicative scatter correction (MSC), standard normal variate (SNV), and Savitzky-Golay spectra derivatization using first (FD) or second derivative (SD) and mean centering (MC). Moreover, the selection of spectral region is a key step to build a calibration model. For that, iPLS strategy was used (Norgaard et al., 2000). Additionally, the selection of an optimum number of latent variables was crucial to produce a robust, reliable and unbiased model. To select the optimum number of latent variables leave-one-out cross validation (CV) was employed according to the root mean square error of cross validation (RMSECV) values. Outliers were identified by high values of $\mathrm{Q}$ residual and the Hotelling $\mathrm{T}^{2}$ values.

The performance of PLS-NIR models was evaluated according to the root mean square error of prediction (RMSEP), which permits to compare predicted values, for an independent data set of samples, with data found by the reference procedure. The relative root mean square error of prediction (RRMSEP), defined as the RMSEP divided by the average concentration value of the prediction set, was considered to evaluate the relative accuracy of the models and the residual predictive deviation (RPD) calculated as the ratio between the standard deviation (SD) of the prediction set and the RMSEP values (Williams \& Daves, 1995).

\section{Results and discussion}

\subsection{Salmon oil NIR spectra}

Fig. 1 shows NIR spectra of all salmon oil samples considered through this study. Absorption bands around 8560 and $8261 \mathrm{~cm}^{-1}$ are associated with second overtones of $\mathrm{C}-\mathrm{H}$ stretching vibrations of $\mathrm{CH}_{3}$ and $\mathrm{CH}_{2}$, respectively, while those at 7181 and $7065 \mathrm{~cm}^{-1}$ are due to the combination band of $\mathrm{C}-\mathrm{H}$. The peaks at 5792 and $5676 \mathrm{~cm}^{-1}$ arise from the first overtone of $\mathrm{C}-\mathrm{H}$ stretching vibrations of $-\mathrm{CH}_{3},-\mathrm{CH}_{2}$ and $-\mathrm{HC}=\mathrm{CH}$ groups. Small peaks at $4654 \mathrm{~cm}^{-1}$ are associated with combination bands of $\mathrm{C}-\mathrm{H}$ and $\mathrm{C}-\mathrm{O}$ stretching vibration (Sinelli, Cerretani, Di Egidio, Bendini, \& Casiraghi, 2010; Armenta, Garrigues, \& de la Guardia, 2007).

\subsection{PLS-NIR models}

Different PLS-NIR models were developed in order to predict $\mathrm{i}$ ) the main fatty acids in salmon oil as PA, OA, ALA and LA acids; ii) fatty acid families as Omega-3, Omega-6, PUFAs, MUFAs and SFAs and; iii) lipid classes as TAGs, DAGs, FFAs and ergosterol.

To build PLS-NIR models, 38 salmon oil samples, selected by K-S algorithm, were used as calibration set. Different spectral pretreatment with different regions were test to found the best PLSNIR models as abovementioned. In all cases, SNV, FD with a smoothing of 13 points and MC were adopted as signal preprocessing. iPLS was employed to select the spectral region and, to do it, spectra were divided into intervals of 494 variables. Fig. 2a shows the mean NIR salmon oil spectrum with regions selected automatically by using iPLS considering omega-3 compounds. To build PLS-NIR models, using the aforementioned spectral range, the optimum number of LVs was selected according to the RMSECV values (See Fig. 2b).

Fig. 2c shows the regression between predicted and reference values for Omega-3 compounds, obtaining a good distribution of calibration and validation points, which were placed close to the optimum regression line with an intercept of 0 and a slope of 1 . Moreover, PCA was built as data exploratory. Fig. 2d presents the scores plot for first, second and third principal components obtained from PCA for salmon oil samples after SNV, FD and MC pre-treatment with the selected region. The first third principal components represented $96.5 \%$ of the explained variance, being $71.79,14.43$ and $10.28 \%$ for PC1, PC2 and PC3, respectively. PCA indicates that samples of calibration set could be used to build PLS-NIR model for Omega-3 determination due to their representativity of the whole data set.

The mean, minimum and maximum concentration values of the studied compounds in calibration and validation sets, using CG-FID and HPTLC as reference data, are shown in Table 1 . It must be noticed that one sample was removed from all calibration sets and two samples from all validation sets due to their high $\mathrm{Q}$ resid- 
Version définitive du manuscrit publiée dans / Final version of the manuscript published in :

Food Chemistry (2018), Vol. 239, p. 865-871, DOI: 10.1016/j.foodchem.2017.06.158

Journal homepage : http://www.elsevier.com/locate/foodchem

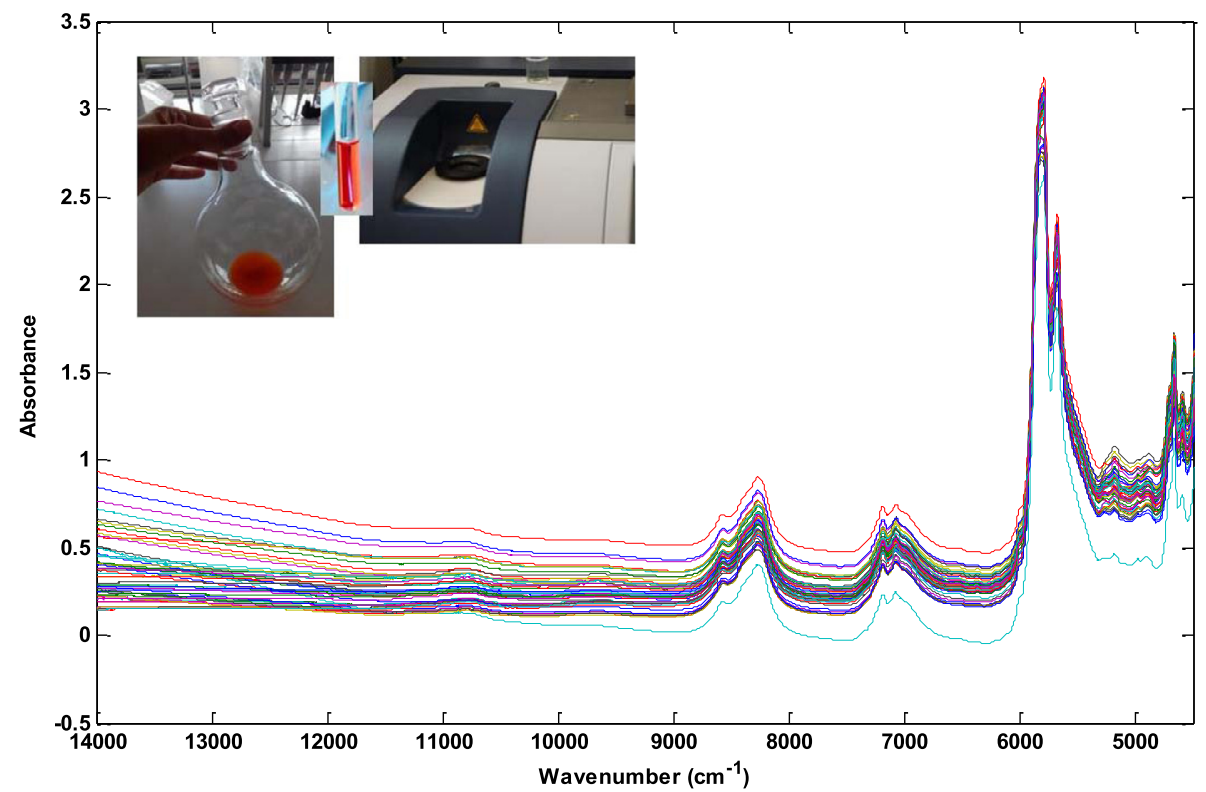

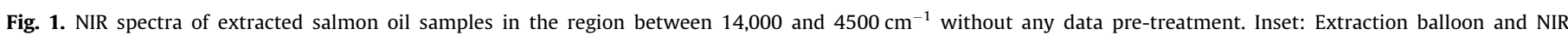
measurement cell.
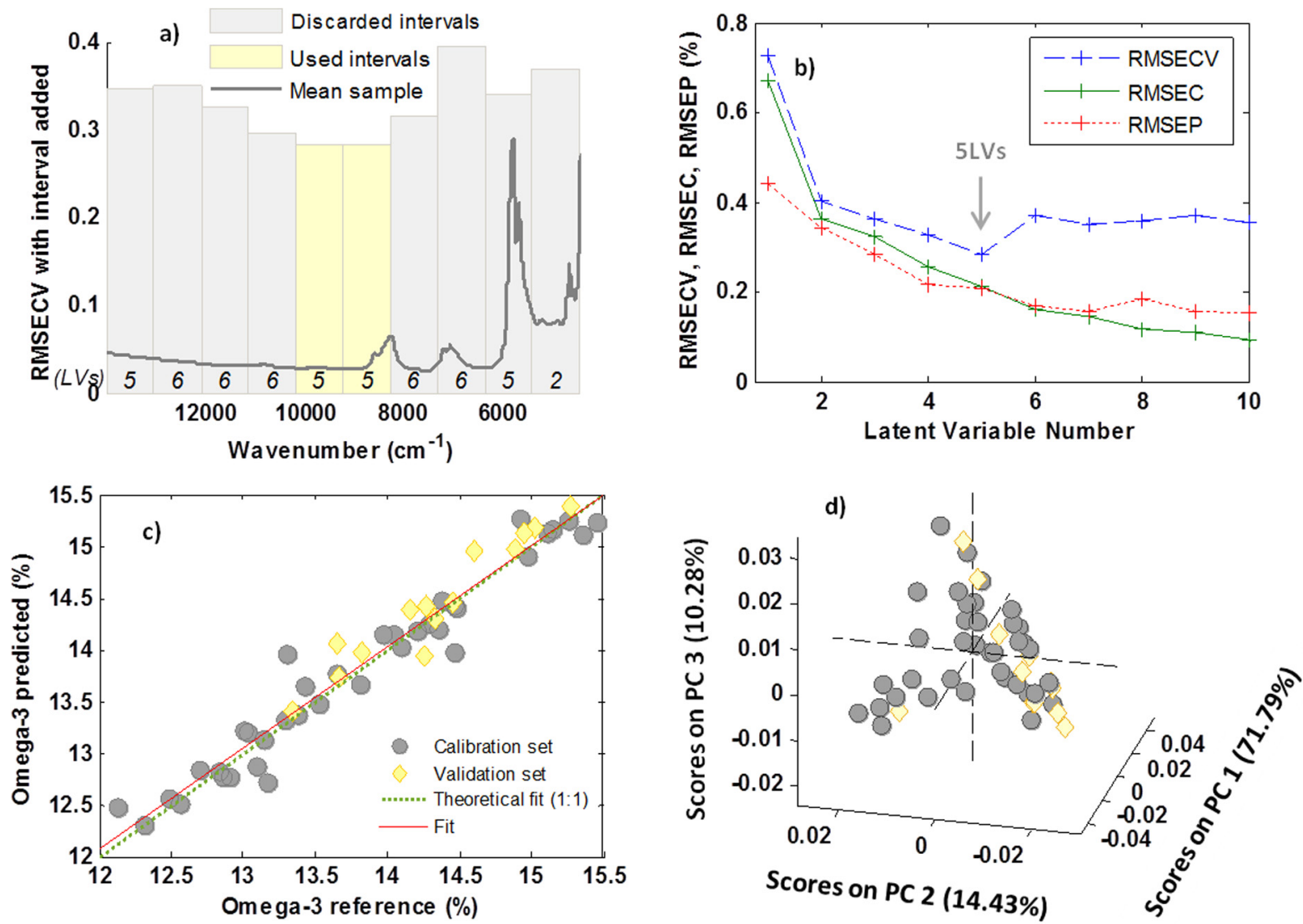

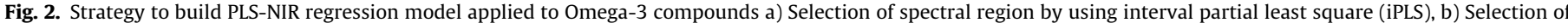

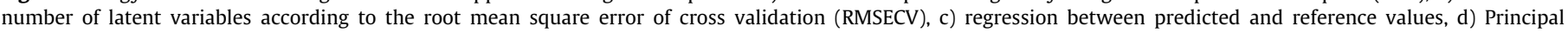
component analysis (PCA) scores plot employed in order to ensure the representativity of calibration set.

ual values and the Hotelling $\mathrm{T}^{2}$ values. One additional sample was eliminated from OA and MUFAs calibration sets for the same reason. The most important calibration parameters of the developed PLS-NIR models for fatty acids and lipid class determination are shown in Table 2. In this table there are indicated the spectral region and number of LVs used for model built for each compound, RMSEC, RMSECV, and coefficients of determination of calibration $\left(R_{\text {Cal }}^{2}\right)$ and cross validation $\left(R_{C V}^{2}\right)$ of samples set. 
Version définitive du manuscrit publiée dans / Final version of the manuscript published in :

Food Chemistry (2018), Vol. 239, p. 865-871, DOI: 10.1016/j.foodchem.2017.06.158

Journal homepage : http://www.elsevier.com!locate/foodchem

Table 1

Concentration ranges of fatty acids and lipids classes in studied fish oil samples corresponding to calibration and validation data sets.

\begin{tabular}{|c|c|c|c|c|c|}
\hline Analyte & Set & Samples & Range $(\% \mathrm{w} / \mathrm{w})$ & Mean value $(\% \mathrm{w} / \mathrm{w})$ & $\mathrm{SD}$ \\
\hline \multirow{2}{*}{ Palmitic acid (PA; C16:0) } & Cal & 37 & $11.19-11.75$ & 11.51 & 0.13 \\
\hline & Val & 14 & $11.28-11.82$ & 11.48 & 0.14 \\
\hline \multirow[t]{2}{*}{ Oleic acid (OA; C18:1) } & Cal & 36 & $37.98-39.63$ & 38.94 & 0.42 \\
\hline & Val & 14 & $37.9-39.44$ & 38.89 & 0.37 \\
\hline \multirow[t]{2}{*}{ Linoleic acid (LA; C18:2n6) } & Cal & 37 & $16.17-17.34$ & 17.01 & 0.26 \\
\hline & Val & 14 & $16.76-17.33$ & 17.11 & 0.15 \\
\hline \multirow[t]{2}{*}{ Linolenic acid (ALA; C18:3n3) } & Cal & 37 & $5.16-5.57$ & 5.36 & 0.13 \\
\hline & Val & 14 & $5.24-5.61$ & 5.44 & 0.11 \\
\hline \multirow[t]{2}{*}{ Omega-3 } & Cal & 37 & $12.12-15.46$ & 13.77 & 0.94 \\
\hline & Val & 14 & $13.35-15.27$ & 14.33 & 0.58 \\
\hline \multirow[t]{2}{*}{ Omega-6 } & Cal & 37 & $18.21-19.62$ & 19.25 & 0.33 \\
\hline & Val & 14 & $18.94-19.58$ & 19.36 & 0.17 \\
\hline \multirow[t]{2}{*}{ Poliunsaturated Fatty Acids (PUFAs) } & Cal & 37 & $30.78-34.76$ & 33.05 & 1.15 \\
\hline & Val & 14 & $32.59-34.85$ & 33.72 & 0.62 \\
\hline \multirow{2}{*}{ Monounsaturated Fatty Acids (MUFAs) } & Cal & 36 & $43.24-45.23$ & 44.31 & 0.51 \\
\hline & Val & 14 & $43.18-44.99$ & 44.20 & 0.42 \\
\hline \multirow[t]{2}{*}{ Saturated Fatty Acids (SFAs) } & Cal & 37 & $19.62-20.22$ & 19.89 & 0.17 \\
\hline & Val & 14 & $19.48-20.17$ & 19.80 & 0.20 \\
\hline \multirow[t]{2}{*}{ Triacilglycerides (TAGs) } & Cal & 37 & $72.63-76.01$ & 74.16 & 1.22 \\
\hline & Val & 14 & $73.20-76.01$ & 75.06 & 0.89 \\
\hline \multirow[t]{2}{*}{ Diacylglycerides (DAGs) } & Cal & 37 & $16.06-18.94$ & 17.43 & 1.17 \\
\hline & Val & 14 & $15.06-18.53$ & 16.57 & 0.93 \\
\hline \multirow[t]{2}{*}{ Free Fatty Acids (FFAs) } & Cal & 37 & $4.98-6.44$ & 5.85 & 0.41 \\
\hline & Val & 14 & $5.16-6.44$ & 5.93 & 0.32 \\
\hline \multirow{2}{*}{ Ergosterol } & Cal & 37 & $2.22-3.12$ & 2.51 & 0.26 \\
\hline & Val & 14 & $2.22-3.0$ & 2.44 & 0.18 \\
\hline
\end{tabular}

SD: Standard deviation.

As it can be seen from data in Table 2 the main part of parameters could be predicted based on a reduced number of latent variables. However for lipids classes, which involve several compounds, 6 LV's were required in the case of FFAs and 7 LV's for the calibration of SFAs.

Coefficients of determination for the established calibration models varied between 0.72 till 0.99 , independently of the consideration of a single compound or a lipid class, and particularly low $\mathrm{R}^{2}$ values for cross validation were found for SFAs and palmitic acid. However coefficients of determination for the validation set of samples varied between 0.58 and 0.98 , thus indicating that low $R_{\mathrm{CV}}^{2}$ were probably due to the limited range of variability of the concentrations of considered compounds.

\subsection{PLS-NIR prediction capability}

To evaluate the predictive capability of PLS-NIR models for the determination of fatty acids and lipid class in salmon oils, samples of the validation set, not employed during the calibration step, were used for this purpose. The regression equations between PLS-NIR predicted values and reference ones are summarized in Table 3.

Table 2

Parameters of PLS-NIR models developed for the determination of fatty acids and lipid classes in salmon oil.

\begin{tabular}{|c|c|c|c|c|c|c|c|c|c|c|}
\hline \multirow[b]{2}{*}{ Analyte } & \multirow[b]{2}{*}{$\begin{array}{l}\text { Spectral } \\
\text { region }\left(\mathrm{cm}^{-1}\right)\end{array}$} & \multirow[b]{2}{*}{ LV } & \multicolumn{4}{|c|}{ Calibration set } & \multicolumn{4}{|c|}{ Validation set } \\
\hline & & & $\begin{array}{l}\text { RMSEC } \\
(\% \mathrm{w} / \mathrm{w})\end{array}$ & $\mathrm{R}^{2} \mathrm{Cal}$ & $\begin{array}{l}\text { RMSECV } \\
(\% \mathrm{w} / \mathrm{w})\end{array}$ & $\mathrm{R}^{2} \mathrm{CV}$ & $\begin{array}{l}\text { RMSEP } \\
(\% \mathrm{w} / \mathrm{w})\end{array}$ & $\begin{array}{l}\mathrm{R}^{2} \\
\text { Pred }\end{array}$ & RRMSEP (\%) & RPD \\
\hline Palmitic acid (PA; C16:0) & $\begin{array}{l}13044.5-12093.7 \\
5422.9-4472.2\end{array}$ & 3 & 0.07 & 0.72 & 0.09 & 0.55 & 0.09 & 0.58 & 0.78 & 1.54 \\
\hline Oleic acid (OA; C18:1) & $6375.7-5424.9$ & 5 & 0.14 & 0.88 & 0.18 & 0.80 & 0.29 & 0.65 & 0.75 & 1.27 \\
\hline Linoleic acid (LA; C18:2-n6) & $5422.9-4472.2$ & 4 & 0.06 & 0.95 & 0.09 & 0.86 & 0.09 & 0.70 & 0.50 & 1.76 \\
\hline Linolenic acid (ALA; C18:3-n3) & $\begin{array}{l}13997.1-13046.4 \\
11139.1-10188.3 \\
7328.4-6377.6 \\
5422.9-4472.2\end{array}$ & 4 & 0.05 & 0.85 & 0.07 & 0.7 & 0.07 & 0.60 & 1.35 & 1.48 \\
\hline Omega-3 & $10186.4-8282.9$ & 5 & 0.21 & 0.95 & 0.28 & 0.91 & 0.20 & 0.92 & 1.41 & 2.84 \\
\hline Omega-6 & $5423.0-4472.2$ & 4 & 0.07 & 0.96 & 0.11 & 0.89 & 0.09 & 0.73 & 0.51 & 1.71 \\
\hline Poliunsaturated Fatty Acids (PUFAs) & $6375.7-4472.2$ & 5 & 0.19 & 0.97 & 0.35 & 0.91 & 0.26 & 0.91 & 0.76 & 2.41 \\
\hline Monounsaturated Fatty Acids (MUFAs) & 13997.1-4472.2 & 3 & 0.19 & 0.86 & 0.25 & 0.75 & 0.30 & 0.61 & 0.69 & 1.39 \\
\hline Saturated Fatty Acids (SFAs) & $\begin{array}{l}11139.1-10188.3 \\
7328.4-6377.6\end{array}$ & 7 & 0.08 & 0.74 & 0.13 & 0.40 & 0.12 & 0.63 & 0.62 & 1.62 \\
\hline Triglycerides (TAGs) & $5422.9-4472.2$ & 4 & 0.25 & 0.96 & 0.34 & 0.92 & 0.22 & 0.94 & 0.29 & 4.00 \\
\hline Diglycerides (DAGs) & $\begin{array}{l}11139.1-10188.3 \\
5422.9-4472.2\end{array}$ & 4 & 0.27 & 0.95 & 0.40 & 0.88 & 0.29 & 0.90 & 1.78 & 3.16 \\
\hline Free Fatty Acids (FFAs) & $13997.1-4472.2$ & 6 & 0.05 & 0.99 & 0.09 & 0.95 & 0.08 & 0.96 & 1.32 & 4.10 \\
\hline Ergosterol & 13997.1-4472.2 & 3 & 0.04 & 0.98 & 0.05 & 0.97 & 0.03 & 0.98 & 1.12 & 6.44 \\
\hline
\end{tabular}

LV: number of latent variables.

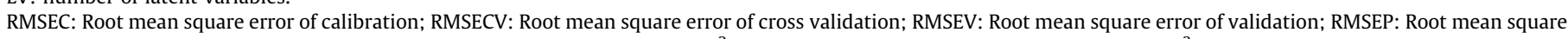

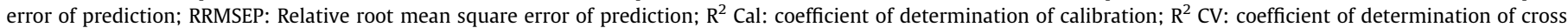
validation; $\mathrm{R}^{2}$ Val: coefficient of determination of validation; $\mathrm{R}^{2}$ Pred: coefficient of determination of prediction; RPD: residual predictive deviation. 
Version définitive du manuscrit publiée dans / Final version of the manuscript published in :

Food Chemistry (2018), Vol. 239, p. 865-871, DOI: 10.1016/j.foodchem.2017.06.158

Journal homepage : http://www.elsevier.com/locate/foodchem

Table 3

Regression between PLS-NIR predicted and reference chromatography values for free fatty acids and lipid classes determination in salmon oil.

\begin{tabular}{|c|c|c|}
\hline \multirow[t]{2}{*}{ Analyte } & \multicolumn{2}{|l|}{ Regression } \\
\hline & Calibration & Prediction \\
\hline Palmitic acid (PA; C16:0) & $y=0.715 x+3.28$ & $\mathrm{y}=0.551 \mathrm{x}+5.13$ \\
\hline Oleic acid (OA; C18:1) & $y=0.887 x+4.39$ & $y=0.832 x+6.32$ \\
\hline Linoleic acid (LA; C18:2 n-6) & $y=0.949 x+0.862$ & $y=0.7380 x+4.45$ \\
\hline Linolenic acid (ALA; C18:3n-3) & $y=0.847 x+0.818$ & $y=0.435 x+3.09$ \\
\hline Omega-3 & $y=0.950 x+0.685$ & $y=0.996 x+0.173$ \\
\hline Omega-6 & $y=0.957 x+0.830$ & $y=0.774 x+4.33$ \\
\hline Poliunsaturated Fatty Acids (PUFAs) & $y=0.972 x+0.918$ & $y=1.126 x-4.13$ \\
\hline Monounsaturated Fatty Acids (MUFAs) & $y=0.860 x+6.21$ & $y=0.570 x+18.83$ \\
\hline Saturated Fatty Acids (SFAs) & $y=0.739 x+5.20$ & $y=0.659 x+6.76$ \\
\hline Triglycerides (TAGs) & $y=0.957 x+3.17$ & $y=0.885 x+8.64$ \\
\hline Diglycerides (DAGs) & $y=0.947 x+0.921$ & $y=0.802 x+3.28$ \\
\hline Free Fatty Acids (FFAs) & $y=0.987 x+0.074$ & $y=0.855 x+0.829$ \\
\hline Ergosterol & $y=0.976 x+0.064$ & $y=0.982 x+0.057$ \\
\hline
\end{tabular}

Note: Equations were obtained from the regression between reference data and those found separately for calibration and external validation.

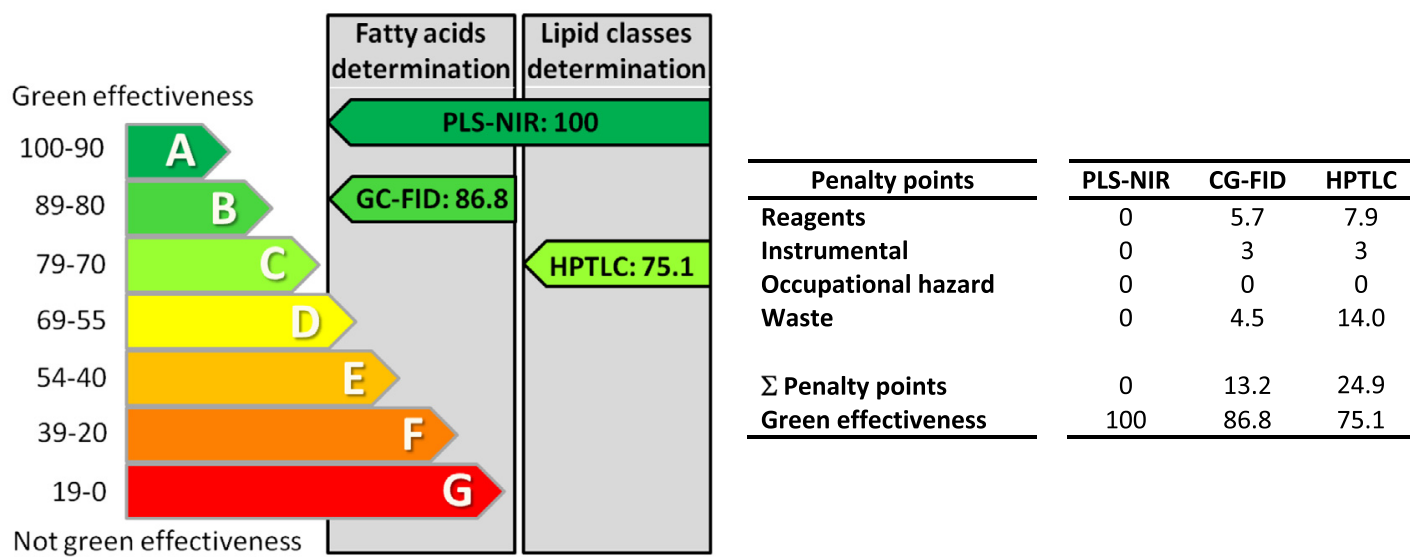

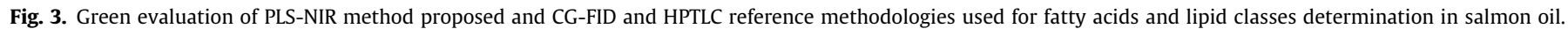

Regression equations approached slope values around 1 and intercept values close to 0 . However it must be noticed that slope values varied between 0.715 and 0.987 for samples employed in the calibration set being slope values between 0.435 , for prediction of linolenic acid, and 0.982 for ergosterol. So, it can be concluded that, in spite of the relatively good values obtained for the RPD (see Table 2) the accuracy of linolenic and palmitic acids, and MUFAs is far to be accurate and thus these parameters could be only predicted as screening level. In the case of MUFAs evaluation the intercept value of the regression between predicted and reference values was also very high with a value of 18.8 .

The main validation parameters of the developed models are indicated in Table 2. Within each model, similar values for the RMSECV and RMSEP were obtained, providing good model performance with correlation of determination of aforementioned fatty acids and lipid class. RRMSEP values between 0.29 and $1.78 \%$ were obtained with RPD values in the range of 1.27 and 6.44. These results demonstrate a good PLS-NIR predictive capability to determine the main compounds of salmon oil. The best results were obtained for lipid classes, especially ergosterol, FFAs, TAGs and DAGs, followed by families of fatty acid determinations as Omega-3 and PUFAs.

\subsection{Evaluation of the method}

The green character of the proposed PLS-NIR methodology was evaluated by using the eco-scale proposed by Galuszka, Konieczka, Migaszewski, and Namiésnik (2012) and modified by Armenta, de la Guardia, and Namiésnik (2017), in a way to established a "Green
Certificate" of the method. Fig. 3 shows the scores according with the Green Certificate to evaluate FT-NIR proposed method and CG-FID and HPTLC methods, used as reference methodologies. This eco-scale is based on the application of colour codes and letters (A to $G$ ), being A class the greenest analytical method. On the basis of a 100 score mark, zero penalty points were assigned to the proposed FT-NIR procedure for simultaneous fatty acids and lipid class determination in the eco-scale. This is because the lack of reagent consumption, waste generation and harmful emissions together with the low energy consume of the employed instrument. Regarding the reference method it is not possible to do the simultaneous determination of fatty acids and lipid classes in a single essay and because of that, two different evaluations were made. For fatty acid determination by CG-FID, 13.2 penalty points were assigned due to use of reagents (5.7), LC-UV energy consumed (3) and wastes (4.5), obtaining a total score of 86.8 . For lipid classes determination by HPTLC, the total score was 75.1 due to the assignation of 24.9 penalty points. Therefore, it can be concluded that PLS-NIR procedure provides a category A Green Certificate method with 100 points score for fatty acids and lipid class determination, while the reference CG-FID method used for fatty acids determination correspond to category B and HPTLC method for lipid classes determination correspond to category $\mathrm{C}$.

\section{Conclusions}

The PLS-NIR method developed permits the simultaneous quantification of several fatty acids, as OA, PA, ALA and LA as well omega-3, omega-6, PUFAs, MUFAs and SFAs, in addition to lipid 
classes as TAGs, DAGs, FFAs and ergosterol in salmon oil avoiding the use of toxic or dangerous reagents together with a drastic reduction in time and energy consumption. However, the accuracy and robustness of the method remains at the screening level for palmitic and linolenic acids and MUFAs. Additionally the RPD value of 1.27 obtained for oleic acid determination in salmon fish oil by PLS-NIR corresponds to a model with a very low predictive ability. So, it can be concluded that PLS-NIR offers a high value screening tool for characterization of salmon fish oil samples with some excellent predictive capability for ergosterol, FFAs, DAGs, TAGs, omega-3 and PUFAs.

Regarding the limitations of the proposed methodology it must be noticed that the lack of sensitivity of NIR spectroscopy affected the capability of this technique to be employed for determination of fatty acids present at low concentrations in the samples and just, fatty acids with relatively high concentration levels could be determined. For this reason direct measurements on salmon tissue samples was not considered. However, taking into consideration that for the characterization of salmon oil by chromatography it is also mandatory a previous extraction of the lipidic fraction, it is clear that NIR spectroscopy could be considered as a fast, direct and not destructive technique for salmon oil sample screening purposes.

\section{Compliance with ethical standards}

Samples from salmon already harvested were acquired in the supermarket. Thus, no ethical permits were needed (Directive 2010/63/EU).

\section{Conflict of interest}

The authors declare that they have no conflict of interest.

\section{Acknowledgments}

M.C acknowledges the FPI grant (BES-2012-055404) and (EEBB-I-16-11854) provided by the Ministerio de Economia y Competividad of the Spanish government. The financial support of the Generalitat Valenciana (Project PROMETEO II 2014/077) and Ministerio de Economia y Competitividad-FEDER (Project CTQ 2014-52841-P) was also acknowledged.

\section{References}

Armenta, S., de la Guardia, M. N. J., \& Namiésnik, J. (2017). Green microextraction. In R. L. M. Valcárcel \& S. Cárdenas (Eds.), Analytical microextraction techniques. Bentham Science.

Armenta, S., Garrigues, S., \& de la Guardia, M. (2007). Determination of edible oil parameters by near infrared spectrometry. Analytica Chimica Acta, 596, 330-337.

Bekhit, M. Y., Grung, B., \& Mjøs, A. (2014). Determination of omega-3 fatty acids in fish oil supplements using vibrational spectroscopy and chemometric methods. Applied Spectroscopy, 68, 1190-1200. http://dx.doi.org/10.1366/13-07210.

Breil, C., Meullemiestre, A., Vian, M., \& Chemat, F. (2016). Bio-based solvents for green extraction of lipids from oleaginous yeast biomass for sustainable aviation biofuel. Molecules, 21(2), 1-14. http://dx.doi.org/10.3390/ molecules21020196.

Calder, P. C., \& Yaqoob, P. (2009). Understanding omega-3 polyunsaturated fatty acids. Postgraduate Medicine, 121(6), 148-157. http://dx.doi.org/10.3810/ pgm.2009.11.2083.

Cascant, M. M., Breil, C., Garrigues, S., de la Guardia, M., Fabiano-Tixier, A. S., \& Chemat, C. F. (2017). A green analytical chemistry approach for lipid extraction: Computation methods in the selection of green solvents as alternative to hexane, anal bioanal chem. Analytical and Bioanalytical Chemistry: In press.
Covas, M. I., Ruiz-Gutierrez, V., de la Torre, R., Kafatos, A., Lamuela-Raventós, R. M., Osada, J., ... Visioli, F. (2006). Minor components of olive oil: Evidence to date of health. Nutrition Reviews, 64, S20-S30. http://dx.doi.org/10.1301/nr.2006.oct. S20.

Cozzolino, D., Murray, I., Chree, A., \& Scaife, J. R. (2005). Multivariate determination of free fatty acids and moisture in fish oils by partial least-squares regression and near-infrared spectroscopy. LWT Food Science and Technology, 38, 821-828. http://dx.doi.org/10.1016/j.lwt.2004.10.007.

de Jong, S. (1993). SIMPLS: An alternative approach to partial least squares regression. Chemometrics and Intelligent Laboratory Systems, 3, 251-263.

Floriano Ribeiro, L., Peralta-Zamora, P., Pereira Ramos, L. P.-N. A., \& Pereira-Netto, A. (2013). Prediction of linolenic and linoleic fatty acids content in flax seeds and flax seeds flours through the use of infrared reflectance spectroscopy and multivariate calibration. Food Research International, 51, 848-854.

Fuchs, B., Süß, R., Teuber, K., Eibisch, M., \& Schiller, J. (2011). Lipid analysis by thinlayer chromatography - A review of the current state. Journal of Chromatography A, 1218, 2754-2774. http://dx.doi.org/10.1016/j.chroma.2010. 11.066 .

Galuszka, A., Konieczka, P., \& Migaszewski, Z. M. N. J. (2012). Analytical eco-scale for assessing the greenness of analytical procedures. Trac-Trend in Analytical Chemistry, 37, 61-72.

Karlsdottir, M. G., Arason, S., Kristinsson, H. G., \& Sveinsdottir, K. (2014). The application of near infrared spectroscopy to study lipid characteristics and deterioration of frozen lean fish muscles. Food Chemistry, 159, 420-427.

Kaur, G., Cameron-Smith, D., Garg, M., \& Sinclair, A. J. (2011). Docosapentaenoic acid (22:5n-3): A review of its biological effects. Progress in Lipid Research, 50(1), 28-34. http://dx.doi.org/10.1016/j.plipres.2010.07.004.

Kennard, R. W., \& Stone, L. A. (1969). Computer aided design of experiments. Technometrics, 11, 137-148. http://dx.doi.org/10.1080/00401706.1969. 10490666.

Kim, K., Nam, Y. A., Sik, H., Hayes, A. W., \& Lee, B. (2014). A-Linolenic acid: Nutraceutical, pharmacological and toxicological evaluation. Food and Chemical Toxicology, 70, 163-178.

Laakso, I., \& Hiltunen, R. (2002). Analysis of fatty acids by gas chromatography, and its relevance to research on health and nutrition. Analytica Chimica Acta, 465, 39-62.

Lavie, C. J., Milani, R. V., Mehra, M. R., \& Ventura, H. O. (2009). Omega-3 polyunsaturated fatty acids and cardiovascular diseases. Journal of the American College of Cardiology. http://dx.doi.org/10.1016/j.jacc.2009.02.084.

Mensink, R. P. (2013). Health effects of saturated fatty acids. In Reference module in biomedical sciences encyclopedia of human nutrition (Vol. 2, pp. 215-219).

Morrison, W. R., \& Smith, L. M. (1964). Preparation of fatty acid methyl esters and dimethylacetals from lipids with boron fluoride-methanol. Journal of Lipid Research, 5, 600-608. Retrieved from http://www.jlr.org/cgi/content/long/5/4/ 600.

Norgaard, L., Saudland, A., Wagner, J., Nielsen, J. P., Munck, L., \& Engelsen, S. B. (2000). Interval partial least-squares regression (iPLS): A comparative chemometric study with an example from near-infrared spectroscopy. Applied Spectroscopy, 54, 413-419.

Olsen, E. F., Rukke, E., Egelandsdal, B., \& Isaksson, T. (2008). Determination of omega- 6 and omega-3 fatty acids in pork adipose tissue with nondestructive Raman and Fourier transform infrared spectroscopy. Applied Spectroscopy, 62, 968-974.

Patterson, E., Wall, R., Fitzgerald, G. F., Ross, R. P., \& Stanton, C. (2012). Health implications of high dietary omega-6 polyunsaturated fatty acids. Journal of Nutrition and Metabolism, 2012. http://dx.doi.org/10.1155/2012/539426.

Sicaire, A. G., Abert Vian, M., Fine, F., Carré, P., Tostain, S., \& Chemat, F. (2015). Experimental approach versus COSMO-RS assisted solvent screening for predicting the solubility of rapeseed oil. OCL Oilseeds and Fats, Crops and Lipids, 22(4).

Simopoulos, A. P. (2002). The importance of the ratio of omega-6 / omega-3 essential fatty acids. Biomedicine Er Pharmacotherapy, 56, 365-379.

Sinelli, N., Cerretani, L., Di Egidio, V., Bendini, A., \& Casiraghi, E. (2010). Application of near (NIR) and mid (MIR) infrared spectroscopy as a rapid tool to classify extra virgin olive oil on the basis of fruity attribute intensity. Food Research International, 43, 369-375.

Williams, P. C., \& Daves, S. (1995). How do we do it: A brief summary of the methods we use in developing near infrared calibrations. In P. C. Williams \& A. M. C. Daves (Eds.), Near infrared spectroscopy: The future waves (pp. 185-188). Chichester, UK: NIR Publications.

Wu, Y., Song, P., Xu, J., Zhang, M., \& Zou, M. (2007). Activation of protein phosphatase $2 \mathrm{~A}$ by palmitate inhibits amp-activated protein kinase. Journal of Biological Chemistry, 282, 9777-9788. http://dx.doi.org/10.1074/jbc. M608310200.

Zhang, H., Wang, Z., \& Liu, O. (2015). Development and validation of a GC - FID method for quantitative analysis of oleic acid and related fatty acids. Journal of Pharmaceutical Analysis, 5, 223-230. 